\title{
Kult und Macht
}

Religion und Herrschaft im syro-palästinensischen Raum. Studien zu ihrer Wechselbeziehung in hellenistisch-römischer Zeit

Hrsg. v. Anne Lykke u. Friedrich T. Schipper

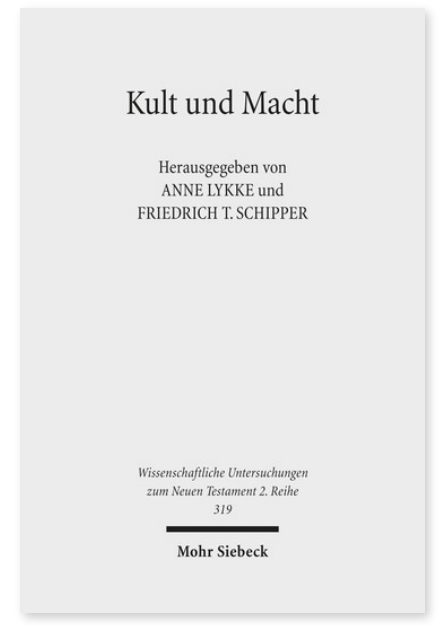

2011. XV, 327 Seiten. WUNT II 319

ISBN 978-3-16-151945-1

DOI 10.1628/978-3-16-151945-1

eBook PDF 104,00€

ISBN 978-3-16-150067-1

fadengeheftete Broschur 104,00€
Im Mai 2008 fand im Rahmen des Graduiertenkollegs »Götterbilder - Gottesbilder - Weltbilder: Polytheismus und Monotheismus in der Welt der Antike« an der Theologischen Fakultät der Georg-August-Universität Göttingen ein internationales Kolloquium zu den Wechselbeziehungen von Religion und Herrschaft im syro-palästinischen Raum in hellenistisch-römischer Zeit statt. Der daraus entstandene Sammelband enthält den Großteil der gehaltenen Vorträge und wurde um einige Beiträge erweitert. Mithilfe eines interdisziplinären Ansatzes wird versucht, die Erträge verschiedener Forschungsdisziplinen zusammenzuführen und auf nachvollziehbare Weise eine Synthese herzustellen, um dadurch alternative Einblicke in die kulturell und religiös pluralistische Landschaft Syro-Palästinas in hellenistisch-römischer Zeit zu ermöglichen.

\section{Mit Beiträgen von:}

Per Bilde, Peter Arzt-Grabner, Konrad Huber, Hans-Peter Kuhnen, Achim Lichtenberger, Anne Lykke, Marion Meyer, Inge Nielsen, Markus Öhler, Simone Paganini, Friedrich Schipper, Robert Wenning

Inhaltsübersicht

Peter Arzt-Grabner: Der »Herr Jesus Christus« und »Caesar, der Herr - über die Anfänge einer Konfrontation - Per Bilde : Der Konflikt zwischen Gaius Caligula und den Juden über die Aufstellung einer Kaiserstatue im Tempel von Jerusalem - Konrad Huber: In der Vollmacht des Satans. Antirömische Herrschaftskritik in der Vision des »Tieres aus dem Meer in Offb 13,1-10 Hans-Peter Kuhnen: Grenzen der Romanisierung. Massebenkulte und die Entstehung islamischer Kultbauten im Vorfeld des Limes Arabiae et Palaestinae - Achim Lichtenberger: Ein tropaeum Traiani in Arabia? Anmerkungen zur Tyche von Petra Anne Lykke : Politische und religiöse Identitäten auf jüdischen Münzen (bis 66 n. Chr.) - Marion Meyer: Die Stadtgöttin von Caesarea Maritima - 'Romanitas' im Bild - Inge Nielsen: Herrscher und Bäder. Die Badegewohnheiten in Palästina in der hellenistischen und früh-römischen Zeit - Markus Öhler: Ethnos und Identität. Landsmannschaftliche Vereinigungen, Synagogen und christliche Gemeinden - Simone Paganini : Priester an der Macht. Beobachtungen zum Verhältnis von Kult und Macht innerhalb des utopischen Gesellschaftsbildes der Tempelrolle - Friedrich T. Schipper: Herodes der Große und die griechische Athletik. Zwischen Hellenisierung, Romanisierung und Herrscherkult - Robert Wenning : Tribale Frömmigkeit und royale Religionspolitik - Gottesverehrung der Nabatäer

Anne Lykke ist Stipendiatin im Graduiertenkolleg »Götterbilder - Gottesbilder - Weltbilder « der Georg-August-Universität Göttingen.

Friedrich T. Schipper ist wissenschaftlicher Mitarbeiter am Institut für Alttestamentliche Wissenschaft und Biblische Archäologie an der Evangelisch-Theologischen Fakultät der Universität Wien.

Jetzt bestellen:

https://mohrsiebeck.com/buch/kult-und-macht-9783161519451?no_cache=1

order@mohrsiebeck.com

Telefon: +49 (0)7071-923-17

Telefax: $+49(0) 7071-51104$ 